\title{
DESIGN AND ANALYSIS OF CONTROLLED SEPIC AND LLC CONVERTERS FOR PHOTOVOLTAIC SYSTEMS
}

\author{
Mohamed Fakhry ${ }^{1}$, Mohamed Saber ${ }^{1}$, Mohamed E. Eltantawi ${ }^{1}$, Sahar S. Kaddah ${ }^{2}$, and Basem M. Badr*3 \\ ${ }^{1}$ Undergrad Student at Electrical Power and Machines Department, College of Engineering, \\ Mansoura University, Egypt \\ ${ }^{2}$ Head of Electrical Engineering Department, Faculty of Engineering, Mansoura University \\ ${ }^{3}$ Test \& Verification Engineer at Genesis Robotic and Motion Technologies, Vancouver, BC, Canada
}

\begin{abstract}
Solar photovoltaic (PV) energy, a nonconventional source, has been a good replacement and best utilized electric source which is clean, non-polluting, safe, and renewable. A power converter is needed to regulate and control the harvested solar power and achieve the required output voltage for various applications. In this paper, two power converters are presented and discussed for $\mathrm{PV}$ systems, which are SEPIC (single-ended primary inductor converter) and LLC resonant converters. Control systems are designed and developed to tune, regulate, and control the output voltage of the SEPIC and LLC converters under various conditions with respect to the load requirements. These proposed control systems are PID (proportional integral derivatives) and FLC (fuzzy logic controller) that are investigated for the nonlinear models of the power converters. MATLAB/SIMULINK is used to model and simulate the proposed PV systems, where the performance of the open loop and closed loop (PID/FLC) systems for the SEPIC and the LLC are analyzed with respect to solar radiation and load conditions. The system efficiency values for SEPIC and LLC for open loop model are $93.3 \%$ and $80.3 \%$, respectively. The simulation results of the proposed PV systems show that the output voltage is controlled and stabled successfully to the required voltage for various loads/applications while the input power from the solar panel and the load applications are varying. The FLC system yields the faster and more robustness response than PID systems.
\end{abstract}

Keywords- Photovoltaic System, SEPIC Converter, LLC Resonant Converter, Fuzzy Logic Control

\section{INTRODUCTION}

Photovoltaic (PV) system is a renewable source that offers several advantages like abundant availability, free from pollution, more reliable and less maintenance. The power generated by PV panel changes with the intensity of solar radiation and operating temperature. As solar energy is versatile with many benefits to people and the environment, it is a major renewable energy source with the potential to meet many of the challenges facing the world. Therefore, solar energy is the one of the most promising and attractive energy sources for the present and future generations, and its share in the energy market is promoted [1-2].

Electric energy is essential to our daily lives. Traditionally, the generation of electric energy involved the combustion of fossil fuels which led to major problems to human beings and planet earth's environment. Accordingly, efforts have recently been focused on finding alternative ways to generate electricity from clean and sustainable energy resources such as sunlight Using PV systems, sunlight can be converted into electrical energy that can be instantly used, stored, or connected to the grid [3-4].

While using the applications of renewable energy, the power converters are used to harvest the output power $\left(V_{i n} \&\right.$ $I_{i n}$ ) from the solar power without fluctuating and ripple free to the loads (grid, charging batteries, etc.). Fig. 1 illustrates the proposed PV system, where we design two different converter topologies that are SEPIC (single-ended primary inductor converter) and LLC resonant converters, where their output power can be used to charge batteries, fed to grid, power various loads. Linear and nonlinear control systems are used to regulate the output voltage for the loads, which are PID (proportional integral derivatives) and FLC (fuzzy logic controller). MATLAB/SIMULINK is used in this work to simulate these control systems for the power converters.

This paper is organized as follows. Section I explains the solar power as a sustainable source for generating electricity. Section II describes the literature survey of using SEPIC \& LLC converters for solar power. The operation principle of the proposed power converters for PV system and the used control systems are discussed in Section III. Simulation results are reported in Section IV. Discussion and analysis of the proposed design systems are illustrated in Section V. Finally, the conclusion of the paper is provided in Section VI. 


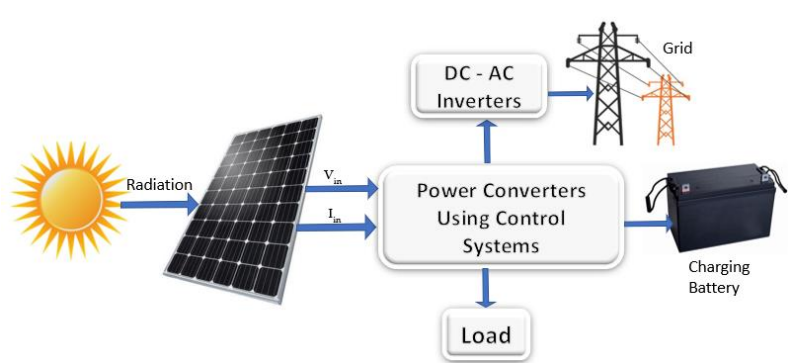

Fig. 1. Proposed PV system

\section{LITERATURE SURVEY}

There are many researchers developed using DC converters for solar power applications. In this section, a survey for SEPIC and LLC converters for PV systems is described.

S. Kumar et al. (2017) designed different DC-DC converters for solar power, which are SEPIC, Boost and CUK converters. They simulated these converters in closed loop using MATLAB/SPS software. The performance simulation results of the converters were discussed to compare between them. It was found that the SEPIC converter had better response (lower ripple) and higher efficiency than the Boost and Cuk converters [5]. E. Durán et al. (2005) designed and simulated a new application of the SEPIC converter to obtain I-V and P-V curves of PV modules. They compared these curves by the Buck-Boost converter, and they found that the SEPIC showed minimum power loss. When a SEPIC structure with coupled inductors was used, the curve I-V of the PV panel was obtained, and the PV stresses were limited [6]. A. Kumar et al. (2018) designed a SEPIC converter for PV applications. Both the software and hardware portion were successfully completed using MATLAB/SIMULINK and the simulation results showed that the converter was capable of producing the ripple free non inverter output. This converter was designed to boost the voltage from $15 \mathrm{~V}$ (from a solar panel) to $24 \mathrm{~V}$ with the efficiency of $89.5 \%$ [2]. K. Uthira et al. (2018) designed and analyzed a closed loop control of solar power fed DC-DC SEPIC converter. They used maximum power point technique (MPPT) to maximize the output power and incremental conductance to observe the P-V characteristic curve. The entire system was simulated using MATLAB/SIMULINK and the simulation results reveal that the converter can provide regulated output voltage in the presence of load and parameter variation [1]. K. V. Narendranath et al. (2017) designed a solar fed SEPIC converter for powering lamps (loads). The circuit was simulated in MATLAB with the voltage of $34 \mathrm{~V}$ input and gives the voltage of $36 \mathrm{~V}$ output. Hardware circuit was constructed and tested for $90 \mathrm{~W}$ with an efficiency of $98.8 \%$ [7]. M. Mohanraj et al. (2014) designed and built a dynamic solar to power a robot using DC-DC SEPIC topology. They used two batteries, their idea was to maintain constant voltage by switching between the two batteries, which was controlled using ARM processor using DPDT relay. Back up battery concept proved to be a maintainable and commercially feasible solution applied to robots [8]. S. Lavanya Devi et al. (2019) designed different DC-DC converters for PV system, which are SEPIC, Buck-Boost, and CUK converters. These converters were simulated using MATLAB/SIMULINK, as open loop systems. The simulation results showed that CUK converter has better performance than the other converters in terms of total harmonic distortion and efficiency for PV systems [9]. M. Oudda et al. (2016) designed and built a SEPIC converter for solar power system, which was controlled by the FLC. Their system was simulated and tested under variation in temperature and solar irradiation. Their study had successfully demonstrated the design, analysis, and suitability of FLC for SEPIC converter [10]. T. G L Krishna Reddy et al. (2013) designed two various closed loop techniques of SEPIC converter for PV panel which are current mode control and PI (proportional integral) control. Their system has been simulated using MATLAB/SIMULINK simulator and the simulation results showed that the current mode controller gives the better result compared to the PI controller [11]. K. Divya et al. (2014) designed and built an improved MPPT of PV system using deterministic particle swarm optimization (DPSO) technique. SEPIC converter was used to boost up the voltage of the system. Simulation results showed that DPSO gives the best result under partial shading condition [12]. R. Pazhampilly et al. (2015) designed and built incremental conductance based MPPT. Their idea was to track MPP exactly with fast response. They used SEPIC and Boost converters to boost up the output voltage and compared between them. Their system was simulated using MATLAB/Xilinx system. Simulation results showed that the SEPIC converter-based PV power generation was more efficient than boost converter-based power generation unit [13]. S. Venkatesh et al. (August 2017) designed and built a project involving the implementation of PV water pumping system with the usage of SEPIC converter and induction motor. Their system was obtained under fixed solar irradiation. Their system was modelled in MATLAB/ SIMULINK, SIMSCAPE toolboxes and dSPACE. The simulation results found that their system was able to produce 3-phases AC output and it can run an induction motor [14]. M. Subashini et al. (2018) designed and built a solar PV fed SEPIC converter under P \& O (Perturb $\&$ Observe) of the MPPT control. They explored the choice of SEPIC converter. They also studied the nature of dynamics from the converter. The performance of the circuit was simulated using MATLAB. Their system presented a higher tracking and conversion efficiency [15]. K. Mohanraj et al. (2017) designed and built a three level SEPIC converter for hybrid wind-solar energy systems. A control strategy was described to overcome switching disadvantages of two level SEPIC converter. The performance and operation of the converter was simulated with MATLAB simulation. Simulation results found that three level SEPIC converters are advantageous when compared to two level converters [16].

O. Abdel-Rahim et al. (2020) designed a fixed frequency predictive-MPPT for phase-shift modulated LLC resonant converters to be used as the first stage in a PV micro-inverter. Hardware prototype was developed and simulated using 
MATLAB/SIMULINK platform. Their system demonstrated several advantages over other MPPT techniques and achieved the maximum available power from the PV module with an efficiency around 99\% [17]. H. Watanabe et al. (2019) designed a DC-AC power converter with an LLC resonant converter for a PV micro-inverter application. This converter consisted of the LLC resonant converter, the active power decoupling circuit, and the current source inverter. The experimental results showed that the double-line frequency ripple was compensated by the small capacitor using the decoupling circuit. The efficiency of the LLC converter was improved by $1 \%$ when the litz wires have a lot of strands in comparison of using normal wires (94.1\%) [18]. M. Uno et al. (2019) designed a differential power processing converter using a LLC resonant voltage multiplier and voltage divider. The converter reduced voltage stresses of switches and capacitors. The design converter was tested and verified using four PV panels connected in series, where the emulating partial conditions were employed, and the efficiency improved (97\%) [19]. C. Chang et al. (2013) designed a high-efficiency LLC resonant DC-DC converter using solar array simulator (SAS). The proposed converter has zero voltage switching (ZVS) operation of the primary switches and zero current switching (ZCS) operation of the rectifier diodes. Various resonant topologies achieved satisfied efficiency but had problems in output voltage with respect to the load conditions. The proposed SAS with LLC resonant converter had smaller circulating energy than other resonant topologies, and the output impedance of the converter could be regulated from zero to infinite by applying frequency modulation control. The experimental results showed that the SAS provided the maximum system efficiency around $92.5 \%$ [20]. J. Jung et al. (2007) designed and developed an LLC resonant topology to derive optimal efficiency and design for wide input ranges and load variations. The LLC design was based on ZVS and ZCS conditions of primary switches and output diode rectifiers, respectively. The experimental results showed the efficiency and cost optimal design rules of the 400 W LLC resonant converter were derived by a primary resonant network, operating frequency, and dead time duration [21]. $\mathrm{H}$. Huang (2010) designed a resonant half-bridge LLC converter, where he introduced a unique analysis tool called first harmonic approximation (FHA) for controlling frequency modulation. FHA was used to define circuit parameters and predict performance, which is then verified through comprehensive laboratory measurements [22].

\section{POWER CONVERTER AND CONTROL Systems DESIGNS}

In this paper, SEPIC and LLC converters are designed for PV systems. Control systems are designed and developed to achieve the required output voltage with respect to the load requirements, which are PID and FLC control systems. MATLAB is used to model and simulate the proposed systems. The following subsections describe the basic operation principle of the power converters and the used control systems.

\section{A. SEPIC Design}

The SEPIC is a DC to DC converter which consists of two inductors and capacitors, diode $(D)$, and a MOSFET switch $(Q)$, as shown in Fig. 2. When the switch $(Q)$ is on, the output diode is reverse biased. The inductor $\left(L_{l}\right)$ is charged by voltage source $\left(V_{\text {in }}\right)$ while the inductor $\left(L_{2}\right)$ is charged by energy transfer capacitor $\left(C_{l}\right)$. When the switch $(Q)$ is turned off, the output diode is getting forward. The $L_{l}$ charges $C_{l}$, and the $L_{2}$ releases the stored energy to output. The voltage values will be high as long as the percentage of duty cycle is high, this is because the longer the inductors charge, the greater their voltage will be. However, if the pulse lasts too long, the capacitors will not be able to charge and the converter will fail [23].

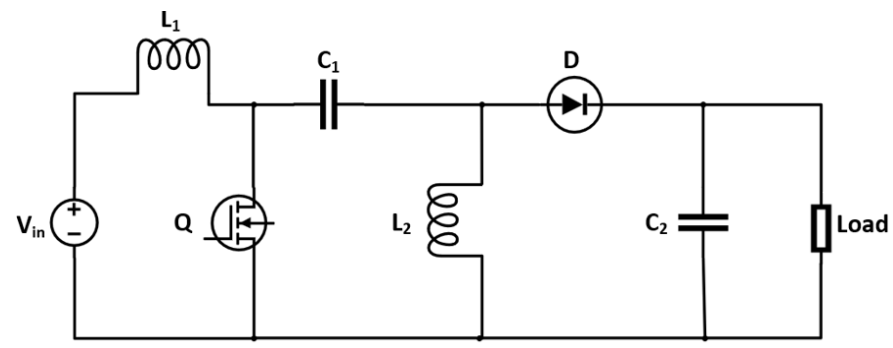

Fig. 2. Circuit diagram of SEPIC converter

The output voltage of the SEPIC converter can be higher or lower than the voltage source without polarity reversal [1-7]. There are two operation modes for the SEPIC, which are CCM (Continuous Conduction Mode) and DCM (Discontinuous Conduction Mode). The derived equations of the SEPIC are described below for calculating the component values with respect to the design requirements. The duty cycle $\left(D_{C}\right)$ of the SEPIC converter is calculated in CCM, which is given by [23]:

$$
D_{C}=\frac{V_{\text {in }}+V_{D}}{V_{\text {out }}+V_{\text {in }}+V_{D}}=\frac{I_{\text {in }}}{I_{\text {out }}-I_{\text {in }}}
$$

where, $V_{D}$ is the forward voltage drop of the Schottky diode. The maximum duty cycle $\left(D_{M A X}\right)$ occurs at $V_{i n(\min )}$ and the minimum duty cycle $\left(D_{M I N}\right)$ occurs at $V_{i n(\max )}$ [24]. In theory, the larger the inductor the better the circuit will operate and reduce the ripple. However, larger inductors are more expensive and have larger internal resistance which will make the converter less efficient. Creating the best converter requires inductors that are large enough to keep the voltage and the current ripple in acceptable range [23]. A rule of thumb is to use $20 \%$ to $40 \%$ of the input current, as computed with the power balance equation, the inductor current is given as [23]:

$L_{1(\min )}=L_{2(\min )}=\frac{1}{2} \times \frac{V_{\text {in }(\min )} \times D_{M A X}}{\Delta I_{L} \times f_{S W}}, \Delta I_{L}=30 \% \times \frac{I_{\text {in }}}{\eta}$

where, $f_{S}$ is the switching frequency and $\eta$ is the efficiency.

To account for load transients, the coupled inductor saturation current rating needs to be at least $20 \%$ higher than the steadystate peak current in the high-side inductor, the peak current in 
the inductor, to ensure the inductor does not saturate, is given by [23]:

$$
\begin{aligned}
& I_{L 1(\text { Peak })}=I_{\text {OUT }} \times \frac{V_{\text {OUT }}+V_{D}}{V_{I N(\min )}}+\frac{\Delta I_{L}}{2}=I_{I N}+\frac{\Delta I_{L}}{2}=I_{I N}\left(1+\frac{30 \%}{2}\right) \\
& I_{L 2(\text { Peak })}=I_{\text {OUT }}+\frac{\Delta I_{L}}{2}
\end{aligned}
$$

The output capacitor is calculated as [24]:

$$
C_{2}>=\frac{I_{\text {out }} \times D_{M A X}}{\Delta V_{R P L} \times f_{S}}
$$

where, $\Delta V_{R P L}$ is the output voltage ripple.

\section{B. Design of LLC Resonant Converter}

Fig. 3 shows the circuit diagram of LLC resonant half-bridge converter, which has three passive components $L_{r}, C_{r}$ and $L_{m}$. A full/half wave rectifier can be used in the secondary side of the circuit which is followed by a capacitive filter.

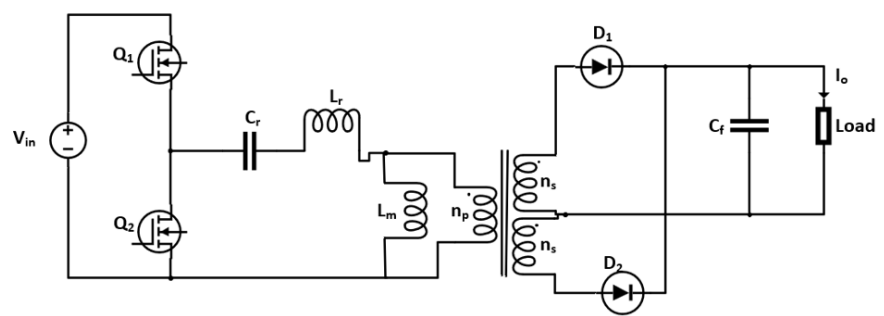

Fig. 3. LLC half-bridge resonant converter

The entire DC characteristic of LLC resonant converter could be divided into ZVS and ZCS regions. The LLC converter should operate at ZVS region to achieve soft switching in MOSFETs which results in low power loss. For this converter, there are two different frequencies which are the highest resonant frequency is formed by the combination of $L_{r} \& C_{r}$ and the lowest resonant frequency is given by the combination of $\left(L_{r}+L_{m}\right) \& C_{r}$. The converter operates between those two resonant frequencies [24]. The main parameters (voltage gain " $k$ ", transformer turns ratio " $n$ ", reflected load resistance " $R_{a c}$ ", quality factor " $Q$ " ratio of primary inductance to resonant inductance " $m$ " and resonant frequency " $f_{r}$ ") of the LLC converter are given as [24]:

$$
\begin{gathered}
k\left(Q, m, f_{x}\right)=\frac{f_{x}^{2}(m-1)}{\sqrt{\left(m f_{x}^{2}-1\right)^{2}+f_{x}^{2}\left(f_{x}^{2}-1\right)^{2}(m-1)^{2} Q^{2}}} \\
n=\frac{\left(V_{\text {in }} / 2\right)}{V_{\text {out }}} \\
R_{a c}=\frac{8 N_{p}^{2} V_{o}^{2}}{\pi^{2} N_{s}^{2} p_{o}} \\
Q=\frac{\sqrt{\frac{L_{r}}{C_{r}}}}{R_{a c}} \\
m=\frac{L_{m}+L_{r}}{L_{r}} \\
f_{r}=\frac{1}{2 \pi \sqrt{L_{r} C_{r}}}
\end{gathered}
$$

\section{Control Systems Design}

Two control systems are designed to control the output voltage $\left(V_{o}\right)$ of the converters to $24 \mathrm{~V}$ that can be used to power electronic circuits, charging batteries, etc. These control systems are PID and FLC that are used to provide the required $V_{o}$ under various conditions of the PV systems, as illustrated in the following section. The output of the controller is compared with a sawtooth signal, where the comparison output is PWM signal that is drive the switches in the power converters, as shown in Fig. 4, where the input voltage source represents the output power from the solar panel.

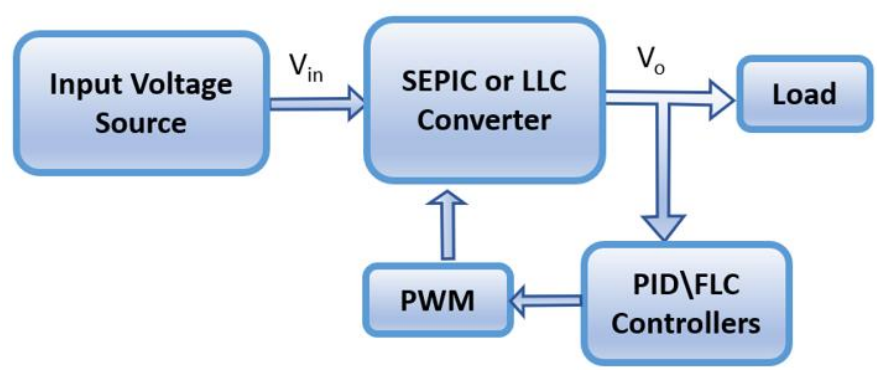

Fig. 4. Block diagram of the power converters with controller

The output of the PID controller $(u(t))$ is function of the error signal $(e(t))$ of the system, as described [25]:

$$
u(t)=K_{P} \cdot e(t)+K_{I} \int e(t) d t+K_{D} \frac{d e(t)}{d t}
$$

There are various techniques for tuning PID gains, based on the mathematical model of the plant. Determining the PID gains depends on the transient and steady-state specifications of the closed-loop system [27]. Ziegler and Nichols technique are the most famous technique for tuning the PID gains, which suggests rules for tuning PID controllers (meaning to set values $K_{p}, T_{i}$ and $T_{d}$ ) based on experimental step responses or based on the value of $K$, that results in marginal stability when only proportional control action is used [26-27]. There are two methods for Ziegler- Nichols tuning, which are based on step response to the plant and critical gain $\left(k_{c r}\right)$. We used the first method approach for tuning the gains, as listed in Table 1.

The FLC is a nonlinear control, which is designed and simulated for the proposed power converters with two inputs (error and change of error). It is a control system based on fuzzy logic and a mathematical system that analyzes analog input values in terms of logical variables that take on continuous values between 0 and 1 , in opposite to classical controllers. It is widely used in machine control applications [27-28]. Three linguistic variables are used for fuzzy inputs such as $\mathrm{N}$ (Negative), Z (Zero) and P (Positive); although, five linguistic variables are used for fuzzy output such as N, Z, P, LN (Large Negative) and LP (Large Positive). Table 2 shows the fuzzy rules based on input variables to infer the output. The three-dimensional representations of the fuzzy rules are shown in Fig. 5 that shows the nonlinearity system. 
Table-1 Ziegler -Nichols Tuning Rule Based on Step Response of Plant (First Method) [26]

\begin{tabular}{|c|c|c|c|}
\hline $\begin{array}{c}\text { Gype of } \\
\text { controller }\end{array}$ & $\mathbf{K}_{\mathbf{p}}$ & $\mathbf{T}_{\mathbf{i}}$ & $\mathbf{T}_{\mathbf{d}}$ \\
\hline $\mathbf{P}$ & $\frac{T}{L}$ & $\infty$ & 0 \\
\hline PI & $0.9 \frac{T}{L}$ & $\frac{L}{0.03}$ & 0 \\
\hline PID & $1.2 \frac{T}{L}$ & $2 L$ & $0.5 L$ \\
\hline
\end{tabular}

Table-2 Rules of FLC system

\begin{tabular}{|c|c|c|c|}
\hline $\begin{array}{c}\text { Error } \\
\text { of error }\end{array}$ & $\mathbf{N}$ & $\mathbf{Z}$ & $\mathbf{P}$ \\
\hline $\mathbf{N}$ & $\mathrm{LN}$ & $\mathrm{N}$ & $\mathrm{Z}$ \\
\hline $\mathbf{Z}$ & $\mathrm{N}$ & $\mathrm{Z}$ & $\mathrm{P}$ \\
\hline $\mathbf{P}$ & $\mathrm{Z}$ & $\mathrm{P}$ & $\mathrm{LP}$ \\
\hline
\end{tabular}

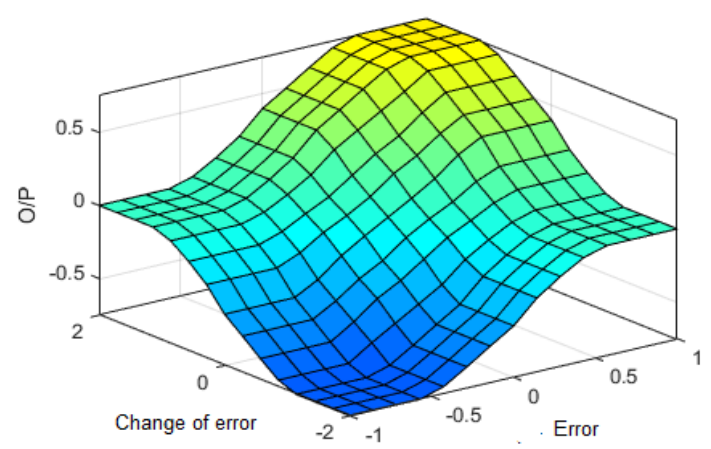

Fig. 5. Three dimensional of the fuzzy rules

\section{Simulation Results}

This section describes the simulation results of MATLAB/SIMULINK. As seen in Fig. 1, the output voltage (harvested from sun radiation) is input to the power converters. The input voltage $\left(V_{i n}\right)$ is set to $17 \mathrm{~V}$ that is the output voltage from a solar panel, and the power converters are designed to output $24 \mathrm{~V}\left(V_{o}\right)$. The following subsections illustrate simulation results of the open loop system (no feedback for the control systems) and closed loop control systems for the SEPIC and LLC systems.

\section{A. Open Loop Results}

The derived equations (1-10) show that the values of the switching frequency and the main parameters for SEPIC and LLC converters. Based on the design requirements ( $V_{\text {in }}$ is $17 \mathrm{~V}$ and $V_{o}$ is $24 \mathrm{~V}$ ), the values of the design parameters for SEPIC and LLC are described as follows. The SEPIC design (Fig. 2) contains $\left(V_{i n}=17 \mathrm{~V}, V_{o}=24 \mathrm{~V}, L_{l}=L_{2}=39 \mu \mathrm{H}, \quad D_{C}=0.59\right.$, $\left.C_{l}=C_{2}=4.7 \mu \mathrm{F}, f_{S}=1 \mathrm{MHz}\right)$. The perimeters of the LLC circuits design (Fig.3) are $\left(V_{i n}=17 \mathrm{~V}, V_{o}=24 \mathrm{~V}, L_{r}=0.9716 \mu \mathrm{H}\right.$,
$L_{m}=2.914 \mu \mathrm{H}, D_{C}=0.5, C_{r}=0.4175 \mu \mathrm{F}, C_{o}=20 \mu \mathrm{F}, f_{S}=250 \mathrm{kHz}$, $\left.N_{p} / N_{s}=14: 48\right)$.

Fig. 6 (a) shows the output voltage of the SEPIC design with over voltage $(40 \mathrm{~V})$. It stabilizes after 12 milliseconds. The settling time $\left(t_{s}\right)$ is 6 milliseconds, and the output ripple voltage is $55 \mathrm{mV}$, as shown in Fig. 6 (b). The output current is 0.8804 $\mathrm{A}$ and the ripple current is $1.825 \mathrm{~mA}$, where the input current is 1.185 A. The output and input powers are $20.83 \mathrm{~W}$ and 22.33 $\mathrm{W}$, respectively, so the efficiency of this converter is $93.3 \%$.

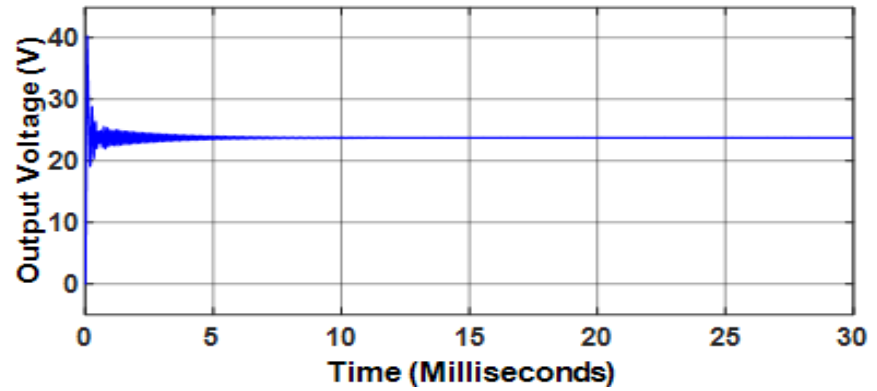

(a)

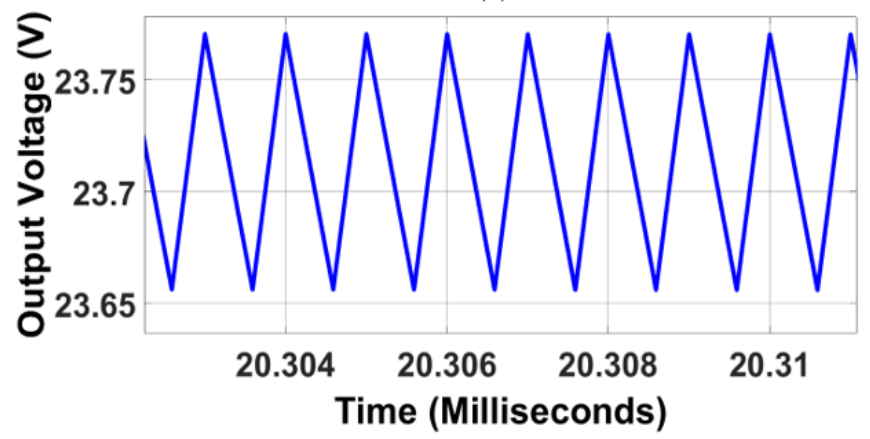

(b)

Fig. 6. Output voltage for the SEPIC (open loop design); (a) full waveform and (b) zoomed in

The $V_{o}$ of the LLC resonant converter stabilizes after 2 milliseconds with settling time (1.5 milliseconds), as shown in Fig. 7 (a). The output ripple voltage is about $2 \mathrm{mV}$, as illustrated in Fig. 7 (b). The output current is $2.397 \mathrm{~A}$ and the ripple current was $0.2 \mathrm{~mA}$. The system efficiency is $80.3 \%$, where the input and output powers are $71.62 \mathrm{~W}$ and $57.48 \mathrm{~W}$.

\section{B. Closed Loop Results}

This section illustrates the simulation results using closed loop control system. As seen in Fig. 4, two control systems are developed to control the output voltage of the converters. The performance analysis of these systems is conducted as follows.

\section{B.1. PID Controller}

The output signals of the PID controller for the SEPIC and LLC $(u(t))$ are compared with a sawtooth signal $\left(250 \mathrm{kHz}, 2 \mathrm{~V}_{\mathrm{P}-}\right.$ P) for LLC and SEPIC to output PWM for the switch, as shown in Fig. 4. The reference signal of the system is set to $24 \mathrm{~V}$. The proposed PV system is simulated when the input voltage is constant and variant at different values, and at different load 
conditions. It is found that the PI controller shows better and faster performance than using PID because of the sluggish response of the derivative gain [27]. Table 3 list the PI gains for SEPIC and LLC converters.

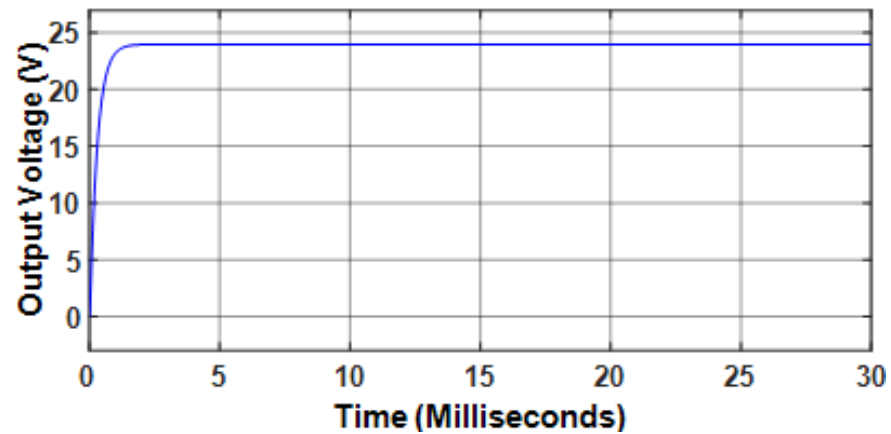

(a)

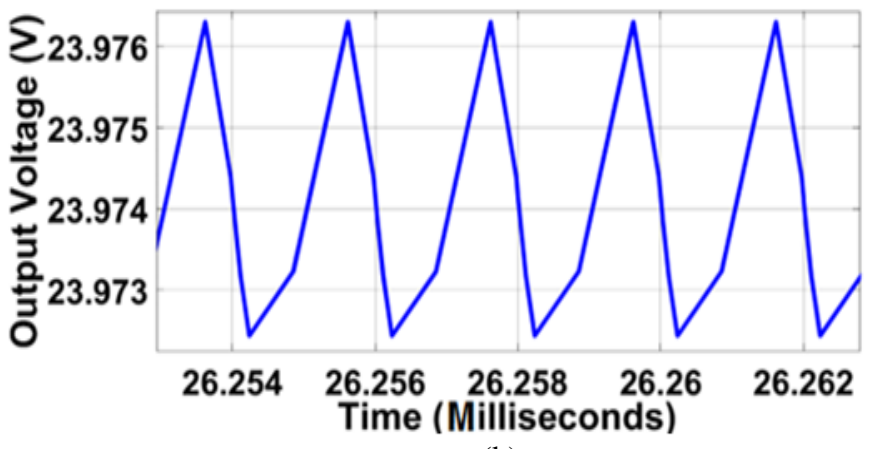

(b)

Fig. 7. Output voltage for the LLC (open loop design); (a) full waveform and (b) zoomed in

Table-3 PI gains of SEPIC and LLC converters

\begin{tabular}{|c|c|c|}
\hline Converter & $\boldsymbol{K}_{\boldsymbol{P}}$ & $\boldsymbol{K}_{\boldsymbol{I}}$ \\
\hline SEPIC & $\mathbf{0 . 6}$ & 600 \\
\hline LLC & 0.113 & 592.79 \\
\hline
\end{tabular}

For the SEPIC design, the $V_{o}$ reaches to $24 \mathrm{~V}$ over 3.5 milliseconds when the input is $17 \mathrm{~V}$ and a resistive load is used, as shown in Fig. 8. There is no over voltage and the ripple voltage is $90 \mathrm{mV}$. The output and input powers are $23.35 \mathrm{~W}$ and $21.26 \mathrm{~W}$, respectively, so the efficiency of this converter is $91 \%$. Due to the sun radiation fluctuations, noise and on/off operations, the input source $\left(V_{i n}\right)$ may be varying at different value. To mimic this behavior, a variant DC source is used instead of the constant source $(17 \mathrm{~V})$. Fig. 9 shows the $V_{o}$ when the input source $\left(V_{\text {in }}\right)$ is $15,17,20,25,30$, and $35 \mathrm{~V}$ sequentially at 5, 10, 15, 20, 25, and 30 milliseconds, respectively. The $V_{o}$ under these input values stables at $24 \mathrm{~V}$. The maximum settling time is 26 milliseconds and maximum overvoltage is $24.8 \mathrm{~V}$ at 16 milliseconds which occurs when the $V_{\text {in }}$ changes from $20 \mathrm{~V}$ to $25 \mathrm{~V}$, as illustrated in Fig. 9.

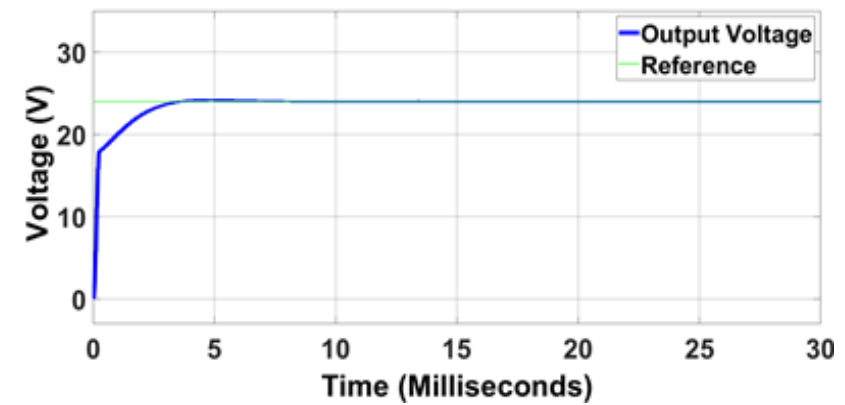

Fig. 8. Output voltage of PID controller for SEPIC when resistive load and constant input $\left(V_{i n}, 17 \mathrm{~V}\right)$ are used

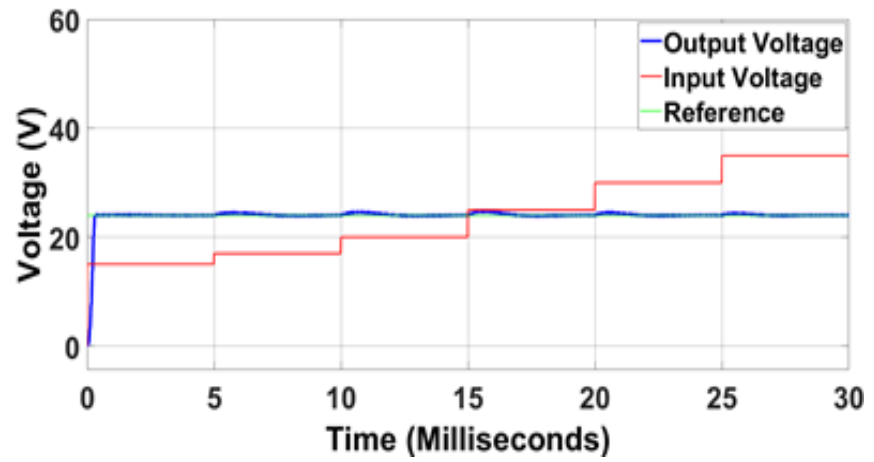

Fig. 9. Output voltage of variant $\mathrm{V}_{\text {in }}$ for SEPIC using PID

Fig. 10 shows the $V_{o}$ of LLC converters when the $V_{\text {in }}$ is $17 \mathrm{~V}$ and a resistive load is used. There is no over voltage and the ripple voltage is $1.89 \mathrm{mV}$. The output and input powers are $57.69 \mathrm{~W}$ and $71.75 \mathrm{~W}$, respectively, so the efficiency of this converter is $80.4 \%$. Fig. 11 illustrates the output voltage value $(24 \mathrm{~V})$ when $V_{\text {in }}$ is varying, as same for SEPIC model. Although, the output voltage is about $28.5 \mathrm{~V}$ and the PI controller could not compensate for this change and disturb in the PV system, where it should achieve the required voltage at $24 \mathrm{~V}$ when the $V_{\text {in }}$ is $20 \mathrm{~V}$. The PI controller shows the linear limitation behavior for nonlinear model.

\section{B.2. Simulation Results Using FLC}

The SEPIC and LLC converters using FLC are simulated which is suitable for a wide load operating conditions and input DC voltage variations as recommended in [27-28]. The output signals of the FLC controller for the SEPIC and LLC are also compared with a sawtooth signal $\left(250 \mathrm{kHz}, 0\right.$ to $\left.1 \mathrm{~V}_{\mathrm{P}-\mathrm{P}}\right)$ for LLC and for SEPIC to output square pulses for the switch and the reference signal of the system is set to $24 \mathrm{~V}$. We used the same conditions of simulating PID for FLC system to compare the output responses, as described in the following section.

The output voltage waveform of the SEPIC converter equals $24 \mathrm{~V}$ with no overshoot when the $V_{\text {in }}$ is a constant value $(17 \mathrm{~V})$, as shown in Fig. 12. The output ripple voltage is $6.5 \mathrm{mV}$. The settling time is about 1.1 milliseconds. The converter efficiency is about $67 \%$, as the output and input powers are $120 \mathrm{~W}$ and $179 \mathrm{~W}$. 


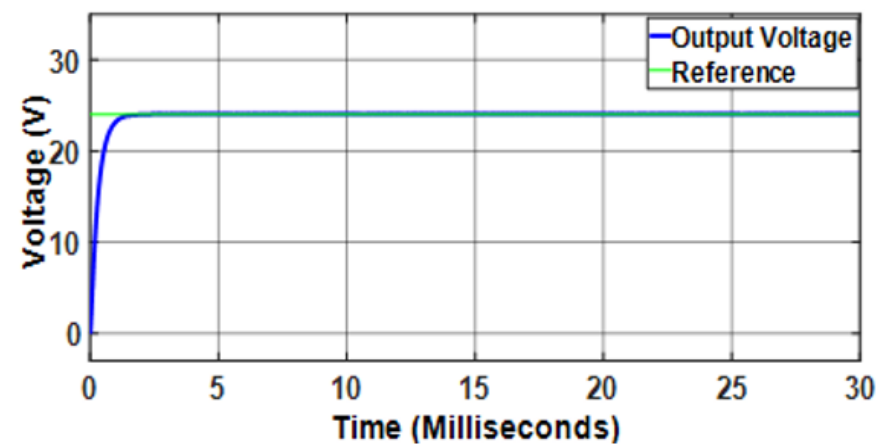

Fig. 10. Output voltage of PID controller for LLC when the resistive load and $V_{\text {in }} 17 \mathrm{~V}$ are used

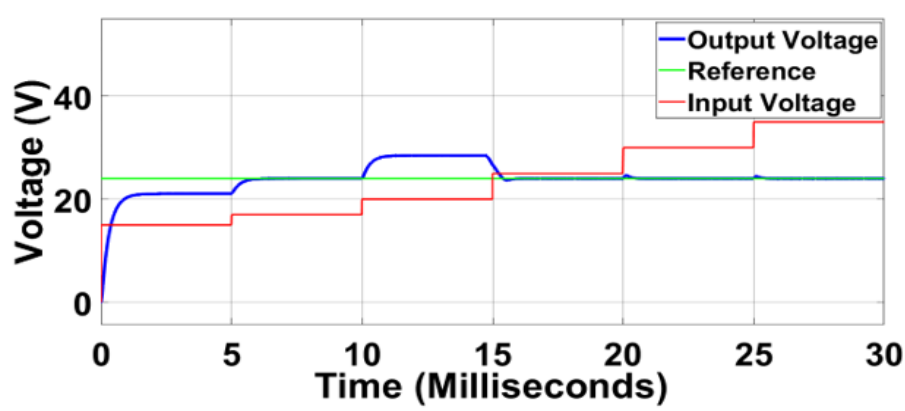

Fig. 11. Output voltage of variant input for LLC controlled by PI

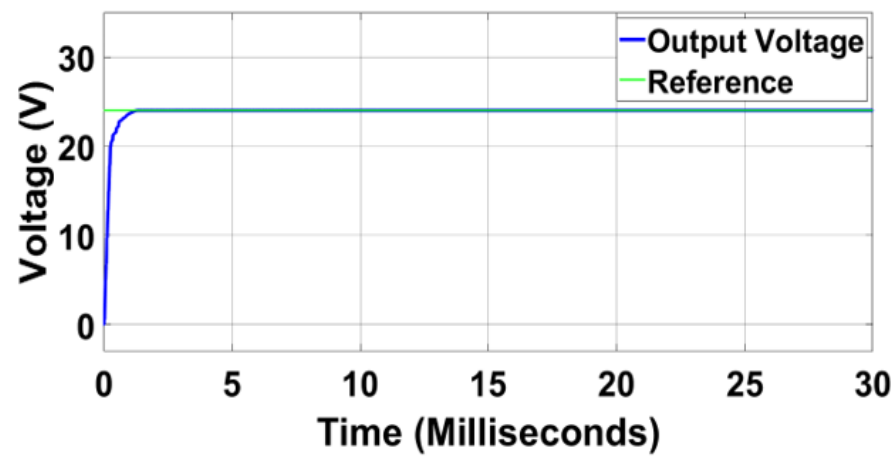

Fig. 12. Output voltage of SEPIC using FLC

Fig. 13 shows the output voltage $(24 \mathrm{~V})$ when the $V_{\text {in }}$ values are $15,17,20,25,30$ and $35 \mathrm{~V}$ sequentially at time $5,10,15$, 20, 25 and 30 milliseconds (same conditions for PID). The settling time is about 1.1 milliseconds where there is no overshoot.

The FLC model for LLC is simulated using the same conditions as PID's. When $V_{\text {in }}$ is a fixed value $(17 \mathrm{~V})$ the $V o$ is stable at $24 \mathrm{~V}$ with settling time (1 millisecond), as shown in Fig. 14. The output ripple voltage is about $1.1 \mathrm{mV}$. The output and input powers are $57.5 \mathrm{~W}$ and $80.26 \mathrm{~W}$, respectively, so the efficiency of this converter is $71.6 \%$. While $V_{i n}$ is varying at different times, the output voltage is being $24 \mathrm{~V}$ with settling time (2.5 milliseconds), as shown in Fig. 15.

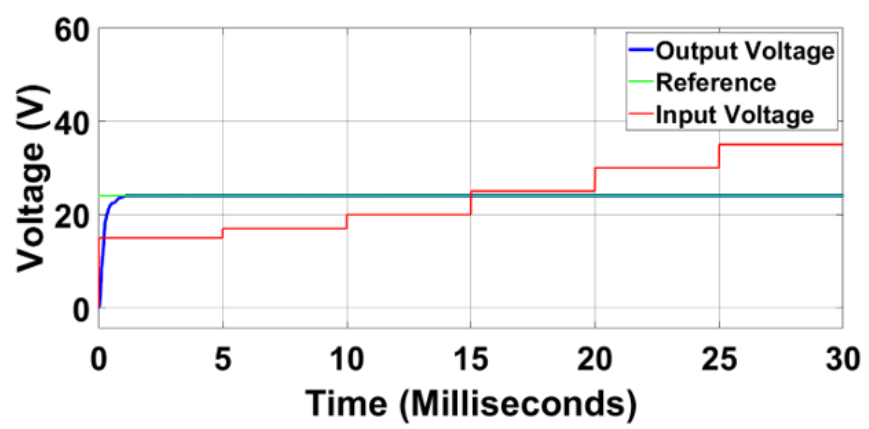

Fig. 13. Output voltage of variant input source for SEPIC using FLC

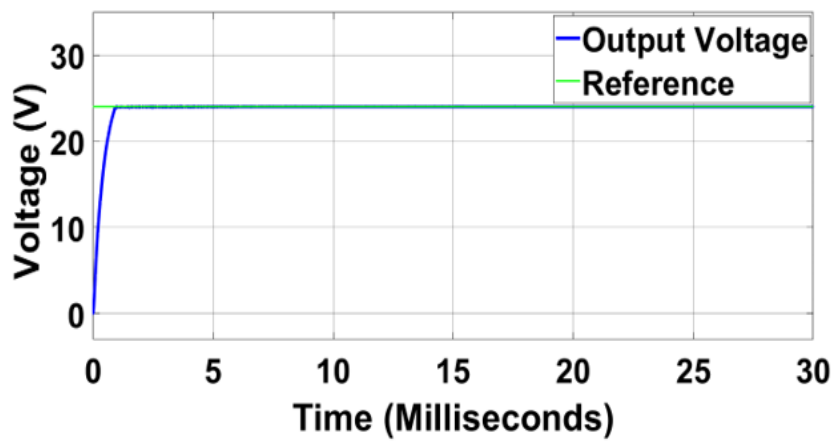

Fig. 14. Output voltage of the FLC controller for LLC

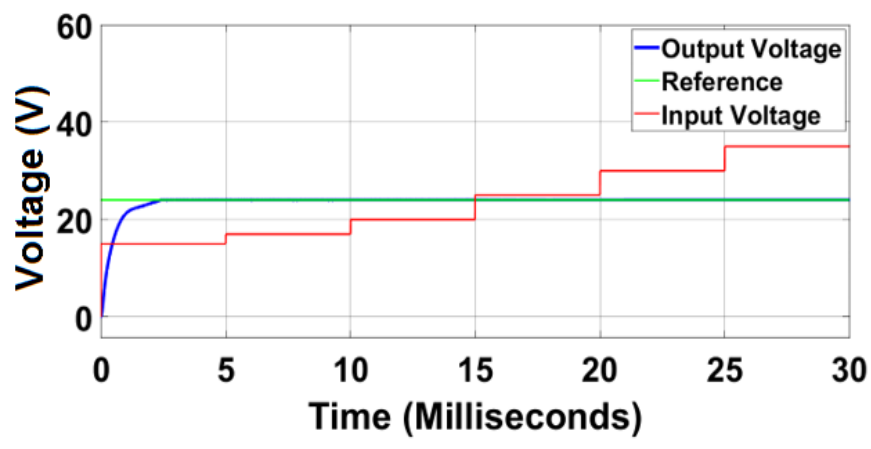

Fig. 15. Output voltage of variant input source for LLC using FLC

\section{DISCUSSION}

In this work, SEPIC and LLC converters have been modeled to achieve the required voltage $(24 \mathrm{~V})$ with different loads and various inputs using open loop and closed loop controller systems. The proposed PV system was simulated for different load conditions, where the open loop systems were modeled using resistive loads to output $24 \mathrm{~V}$. The linear PI control system illustrates limitation of using different load conditions, either using resistive or complex loads. As an example, Fig. 16 shows the simulation results of the SEPIC converter when the load is different resistive (higher/lower than the model) value or complex value. The performance of the SEPIC converter changes, where the overshoot equals $24.85 \mathrm{~V}$, and the output voltage stabilizes after 11 milliseconds and the settling time is about 9 milliseconds when a $100 \Omega$ is used. Fig. 16 (b) shows the output voltage when complex load is used, the complex load (connected in series) consists of $R=10 \Omega, L=1 \mathrm{mH}$ and $C=240$ 
$\mu \mathrm{F}$. The output voltage stabilizes after 13 milliseconds and the overshoot is $33 \mathrm{~V}$. Same behavior is noticed while the load values are changed for the LLC converter as well. The reason of the change of the output performance because of the nonlinearity of the SEPIC and LLC converters, while the FLC achieves the required output $24 \mathrm{~V}$ for the different load values. This is due to the nonlinearity of the FLC which compensates these changes in the nonlinear models of the SEPIC and LLC converters.

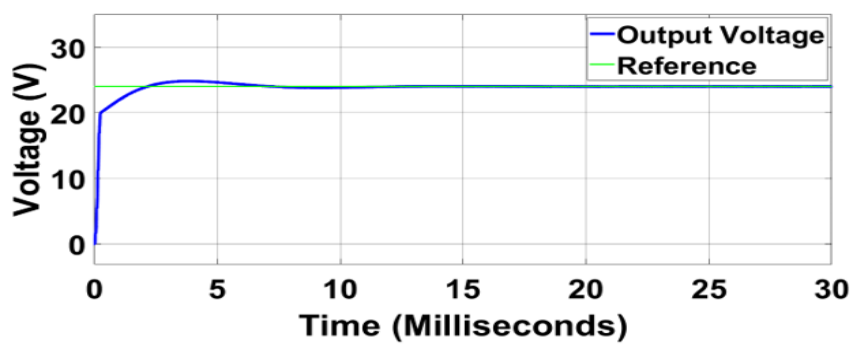

(a)

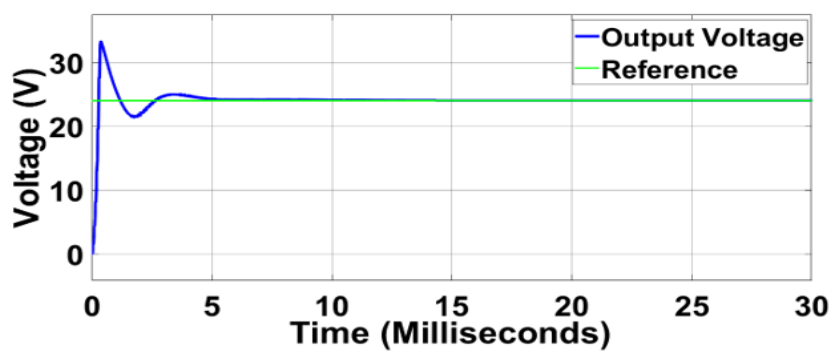

(b)

Fig. 16. Output voltage response of PID controller for SEPIC using; (a) different resistive value and (b) complex load

There are common advantages and disadvantages of SEPIC and LLC converter, as described as follows. The SEPIC converters have advantages such as the output has the same voltage polarity as the input, and it is less complicated than LLC converter. Although, SEPIC converters are non-isolated converters which have pulsating output current and require capacitors with high capacitance and current handling capability. On the other hand, LLC converters are widely used because of its high efficiency with wide load range and Low EMI (electromagnetic interference); however, output regulation is controlled with variations of switching frequency [6-22].

TaError! Reference source not found.ble 4 summarizes comparison open loop and closed loop controller systems (PID and FLC) in a function of time response for SEPIC and LLC converters. Main parameters are used for comparison are ripple voltage, overshoot $(\mathrm{OV})$, rise time $\left(t_{r}\right)$, settling time $\left(t_{s}\right)$, and efficiency. All time parameters are reported in milliseconds, the $\mathrm{OV}$ is reported with respect to the required voltage $(24 \mathrm{~V})$, and the ripple voltage is reported in $\mathrm{mV}$ scale. According to Table 4 , the highest efficiency for SEPIC is $93.28 \%$ (in open loop design), and $80.4 \%$ for LLC when the in PID control system is used. With respect to the comparison performance, advantages, and disadvantages of the converters, the SEPIC and LLC converters can be used for different applications in addition to
PV system, which relay on the requirements of the applications. For example, the LLC converters are good candidate design for battery charging system because of the isolation transformer.

Table-4 Comparison of SEPIC and LLC in open loop and closed loop controllers

\begin{tabular}{|c|c|c|c|c|c|c|}
\hline \multirow{2}{*}{ Controller } & Converter & $\mathbf{t}_{\mathbf{s}}$ & $\mathbf{O V}$ & $\mathbf{t}_{\mathbf{r}}$ & Ripple & Efficiency \\
\hline \multirow{2}{*}{ Open loop } & SEPIC & 6 & 50 & 0.6 & 55 & 93.28 \\
\cline { 2 - 7 } & LLC & 1.5 & 0 & 0.631 & 2 & 80.26 \\
\hline \multirow{2}{*}{ PID } & SEPIC & 3.5 & 0 & 0.6 & 85.5 & 91 \\
\cline { 2 - 7 } & LLC & 1.5 & 0 & 0.634 & 1.89 & 80.4 \\
\hline \multirow{2}{*}{ FLC } & SEPIC & 1.1 & 0 & 0.5 & 6.5 & 67.03 \\
\cline { 2 - 7 } & LLC & 1.1 & 0 & 0.701 & 1.1 & 71.6 \\
\hline
\end{tabular}

\section{CONCLUSION}

This paper focused on designing and analyzing the proposed converters SEPIC and LLC converters for PV systems using two control methods. A stand-alone solar PV system with the proposed converters controlled by a (PID/FLC) controller have been designed and simulated under variant inputs and different loads. MATLAB/SIMULINK was used to model and simulate the design SEPIC and LLC converters, where open loop and closed loop (PID/FLC) control systems were derived according to operation and equations of each converter. We found that FLC control system for SEPIC and LLC converters was able to achieve the required voltage $(24 \mathrm{~V})$ smoothly at different conditions and has better dynamic response than the PID control system due to its nonlinearity. The open loop responses of the SEPIC and LLC converters were designed to boost the voltage from $17 \mathrm{~V}$ input to $24 \mathrm{~V}$ output with efficiency $93.28 \%$ and $80.26 \%$ respectively. However, these converters needed control systems to achieve the required output voltage (24 V) under various conditions, such as sun radiation levels and different load values. The simulation results illustrated that the FLC achieved faster, better, and more robust response that PI control system, as shown in Table 4 and Fig. 16. Either SEPIC or LLC converters are applicable for PV systems, although LLC is preferred to use for battery charging and powering various loads because of the transformer isolation.

\section{CONFLICT OF INTEREST STATEMENT}

The technology, products, views, and opinions expressed by the author are solely theirs, and are in no manner associated with, endorsed by, or attributable to Genesis Robotics and Motion Technologies, LP, or its affiliates.

\section{REFERENCES}

[1] Uthira K., Sandhiya R., Iraianbu P., and Srinivasan R. (2018). Analysis and Design of Solar Power Fed DC-DC SEPIC Converter, IRJET, vol. 7, no. 10, (pp. 3804-3811).

[2] Kumar U., Boobana M., Ramyaa M., Thangam A, Abinaya R, and Seenivasan V. (2018). Designing of 


\section{International Journal of Engineering Applied Sciences and Technology, 2020 \\ Vol. 5, Issue 8, ISSN No. 2455-2143, Pages 54-63 \\ Published Online December 2020 in IJEAST (http://www.ijeast.com)}

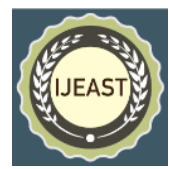

Single Ended Primary Inductance Converter for Solar PV Application Using Arduino Controller, IRJET, vol. 5, no. 4, (pp. 1556-1560).

[3] Abas N., Kalair A., and Khan N. (May 2015). Review of Fossil Fuels and Future Energy Technologies, Futures, vol. 69, (pp. 31-49).

[4] Dollinger B., and Dietrich K. (2013). Storage Systems for Integrating Wind and Solar Energy in Spain, Madrid, Spain. In Proceedings of the International Conference on Renewable Energy Research and Applications (ICRERA) IEEE, 20-23 Oct. 2013, (pp. 361-365).

[5] Kumar S., Kumar R., and Singh N., (March 2017). Performance of Closed Loop SEPIC Converter with DCDC Converter for Solar Energy System, Allahabad, India, $4^{\text {th }}$ International Conference on Power, Control \& Embedded Systems (ICPCES) IEEE, 9-11 March 2017, (pp. 1-6).

[6] Durán E., Enrique J. M., Bohórquez M. A., Cardona M. S., Carretero J. E., and Andújar J. M. (Sept. 2005). A new Application of the Coupled-Inductors SEPIC Converter to Obtain I-V and PV Curves of Photovoltaic Modules, Dresden, Germany, $11^{\text {th }}$ European Conference on Power Electronics and Applications (EPE), 11-14 Sept. 2005, (pp. 11-14).

[7] Narendranath K. V., Viswanath Y., Suresh Babu K., Arunkumar. G, and Elangovan D. (2017). Solar Fed DCDC Single Ended Primary Inductance Converter for Low Power Applications, Tamil Nadu, India. 14th International Conference on Science, Engineering and Technology, 23 May 2017, vol. 263, no. 5.

[8] Mohanraj M., Thottungal R., and Johnson S. (Feb. 2014). Dynamic Solar Powered Robot Using DC-DC SEPIC Topology, IRJET, vol. 3, no. 2, (pp. 402-406).

[9] Devi S. Lavanya, Nagarajan S, Vaishali R. (Jan. 2019). Design, Analysis and Comparison of Suitable Converters for Photovoltaic System, IRJET, vol.7 no-5S2, (pp. 205211).

[10] Oudda M., and Hazzab A. (December 2016). Photovoltaic System with SEPIC Converter Controlled by the Fuzzy Logic, International Journal of Power Electronics and Drive System (IJPEDS), vol. 7, no. 4, (pp. 1283-1293).

[11] Reddy T. G. L. K., Raju R., and Kumar R. (2013). Analysis of SEPIC for PV-Applications Using PI Controller and Current Mode Control, International Journal for Scientific Research \& Development (IJSRD), vol. 1, no. 9, (pp. 1821-1824).

[12] Divya K. and Sugumaran G. (2014). DPSO Based SEPIC Converter in PV System under Partial Shading Condition, World Academy of Science, Engineering and Technology International Journal of Electrical and Computer Engineering, vol. 8, no. 2, (pp. 373-377).

[13] Pazhampilly R., Saravanan S., and Ramesh Babu N. (April 2015). Incremental Conductance Based MPPT for
PV System Using Boost and SEPIC Converter, ARPN Journal of Engineering and Applied Sciences, vol. 10, no. 7, (pp. 2914-2919).

[14] Venkatesh S. and Muthukumar K. (Aug. 2017). SEPIC Converter Based Induction Motor PV Water Pumping System, Tamil Nadu, India. National Conference on Modernization in Engineering Science (NCMES 2K17), 23-24 March, IJIRSET, vol. 6, no 14, (pp. 45-50).

[15] Subashini M. and Ramaswamy M. (Aug. 2018). Exploration of Chaos and Bifurcations in a Solar PV MPPT SEPIC Converter System, IOSR Journal of Engineering (IOSRJEN), vol. 8, no. 8, (pp. 62-69).

[16] Mohanraj K., and Bharathnarayanan S. (June 2017). Three Level SEPIC For Hybrid Wind-Solar Energy Systems, VIT University, Chennai Campus. $1^{\text {st }}$ International Conference on Power Engineering, Computing and Control, 2-4 March, vol. 117, (pp. 120-127).

[17] Abdel-Rahim O., Alamir N., Abdelrahem M., Orabi M., Kennel R., and Ismeil M. A. (March 2020). A Phase-ShiftModulated LLC-Resonant Micro-Inverter Based on Fixed Frequency Predictive-MPPT, Energies, vol. 13, no. 6.

[18] Watanabe H., Itoh J., Koike N., and Nagai S. (Aug. 2019). PV Micro-Inverter Topology Using LLC Resonant Converter, Energies, vol. 12, no. 16.

[19] Uno M., Nakane T., and Shinohara T. (2019). LLC Resonant Voltage Multiplier-Based Differential Power Processing Converter Using Voltage Divider with Reduced Voltage Stress for Series-Connected Photovoltaic Panels under Partial Shading, Electronics, vol. 8 , no. 10 .

[20] Chang C., Chang E., Cheng H. (2013). A High-Efficiency Solar Array Simulator Implemented by an LLC Resonant DC-DC Converter, IEEE Transactions on Power Electronics, vol. 28, no. 6, (pp. 3039-3046).

[21] Jung J. H. and Kwon J. G. (2007). Theoretical Analysis and Optimal Design of LLC Resonant Converter, Aalborg, Denmark. IEEE European Conference on Power Electronics and Applications, 2-5 Sept. 2007, (pp. 1-10).

[22] Huang H. (2010). Designing an LLC Resonant HalfBridge Power Converter, Texas Instruments Power Supply Design Seminar, SEM1900, (pp. 2010-2011).

[23] Falin, J. (2008). Designing DC/DC converters based on SEPIC topology, Texas Instruments.

[24] Yang B. (2003). Topology Investigation for Front End DC/DC Power Conversion for Distributed Power System, Blacksburg, Virginia. Ph.D. Dissertation, Faculty of the Virginia Polytechnic Institute and State University.

[25] Ang K. H., Chong G., and Li Y. (2005). PID Control System Analysis, Design, and Technology, IEEE Transactions on Control Systems Technology, vol. 13, no. 4, (pp. 559-576).

[26] Ogata K. and Yang Y. (2002). Modern control engineering, India: Prentice hall. 
[27] Badr B. M. and Ali W. G. (2011), Fuzzy Control for Nanopositioning Piezoelectric Actuators, Germany: VDM Verlag.

[28] Badr B. M. and Ali W. G. (Feb. 2010). Nanopositioning Fuzzy Control for Piezoelectric Actuators, International Journal of Engineering \& Technology IJET-IJENS, vol. 10, no. 01, (pp. 50-54). 